\title{
Corrigendum to "Effects of Chronic Exposure to Sodium Arsenite on Expressions of VEGF and VEGFR2 Proteins in the Epididymis of Rats"
}

\author{
Dai Yan-Ping, ${ }^{1,2}$ Gao Xiao-Qin, ${ }^{3}$ Ma Xiao Ping, ${ }^{3}$ and Yue Ying Quan ${ }^{3}$ \\ ${ }^{1}$ Department of Histology and Embryology, Guizhou Medical University, Guiyang, Guizhou 550004, China \\ ${ }^{2}$ People's Hospital in Yueyanglou District, Yueyang, Hunan 414000, China \\ ${ }^{3}$ Department of Histology and Embryology, Zunyi Medical College, Zunyi, Guizhou 563000, China \\ Correspondence should be addressed to Dai Yan-Ping; 343620073@qq.com
}

Received 6 September 2017; Accepted 1 October 2017; Published 25 October 2017

Copyright (C) 2017 Dai Yan-Ping et al. This is an open access article distributed under the Creative Commons Attribution License, which permits unrestricted use, distribution, and reproduction in any medium, provided the original work is properly cited.

In the article titled "Effects of Chronic Exposure to Sodium Arsenite on Expressions of VEGF and VEGFR2 Proteins in the Epididymis of Rats" [1], there was an error in the Acknowledgments section, which should be corrected as follows:

This study was supported by Guizhou Province Science and Technology Fund (Qian talents team [2014] no. 4005); Benefits of Science and Technology Plan (according to city fellow word [2014] no. 01); Guizhou Province Science and Technology Fund (Qian LH word) [2015] no. 7568.

\section{References}

[1] D. Yan-Ping, G. Xiao-Qin, M. X. Ping, and Y. Y. Quan, “Effects of Chronic Exposure to Sodium Arsenite on Expressions of VEGF and VEGFR2 Proteins in the Epididymis of Rats," BioMed Research International, vol. 2017, Article ID 2597256, 9 pages, 2017. 

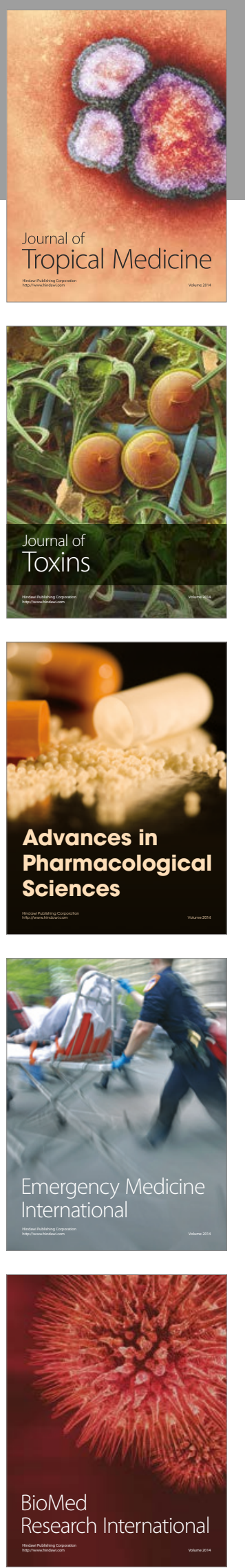
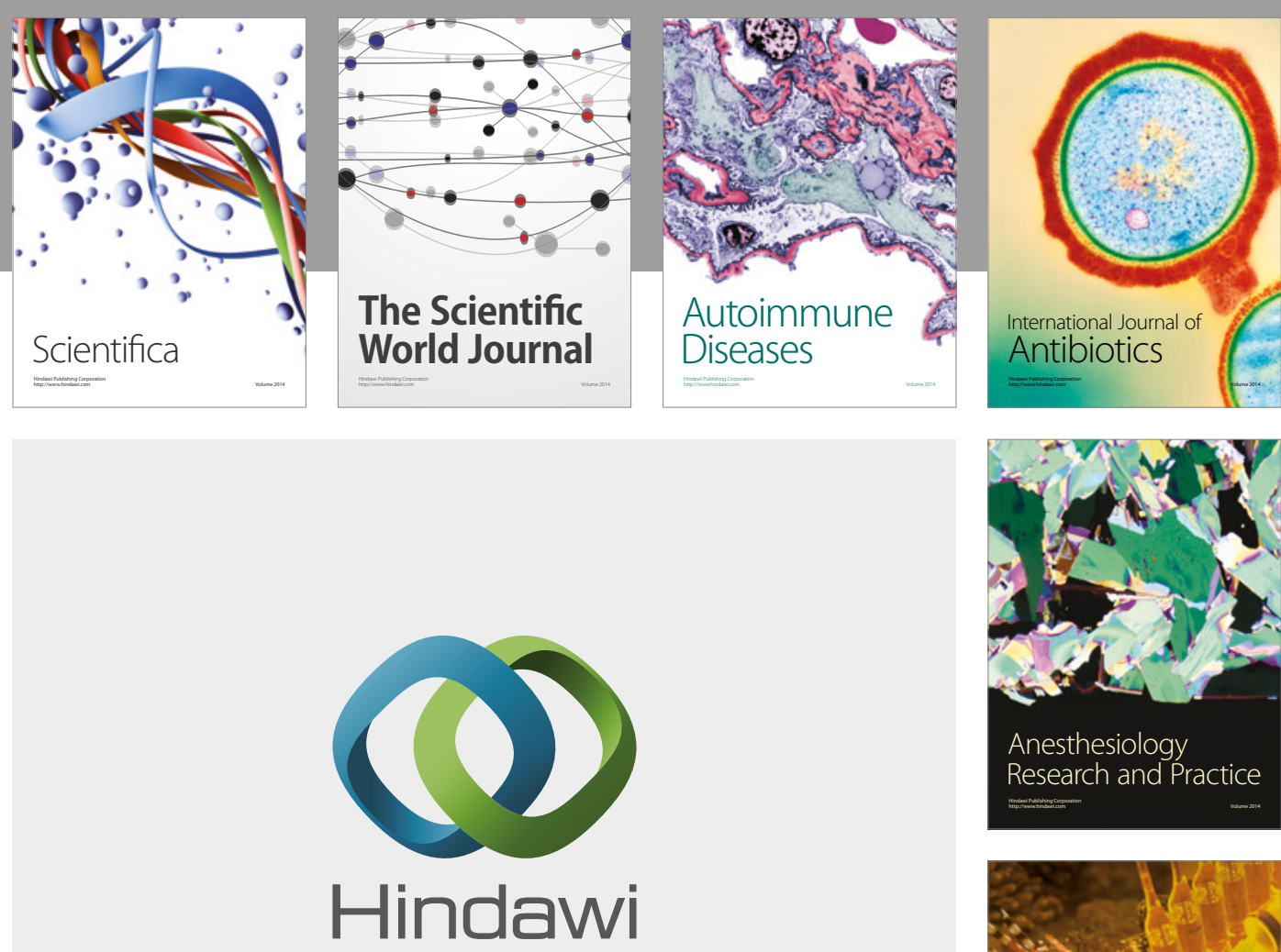

Submit your manuscripts at

https://www.hindawi.com
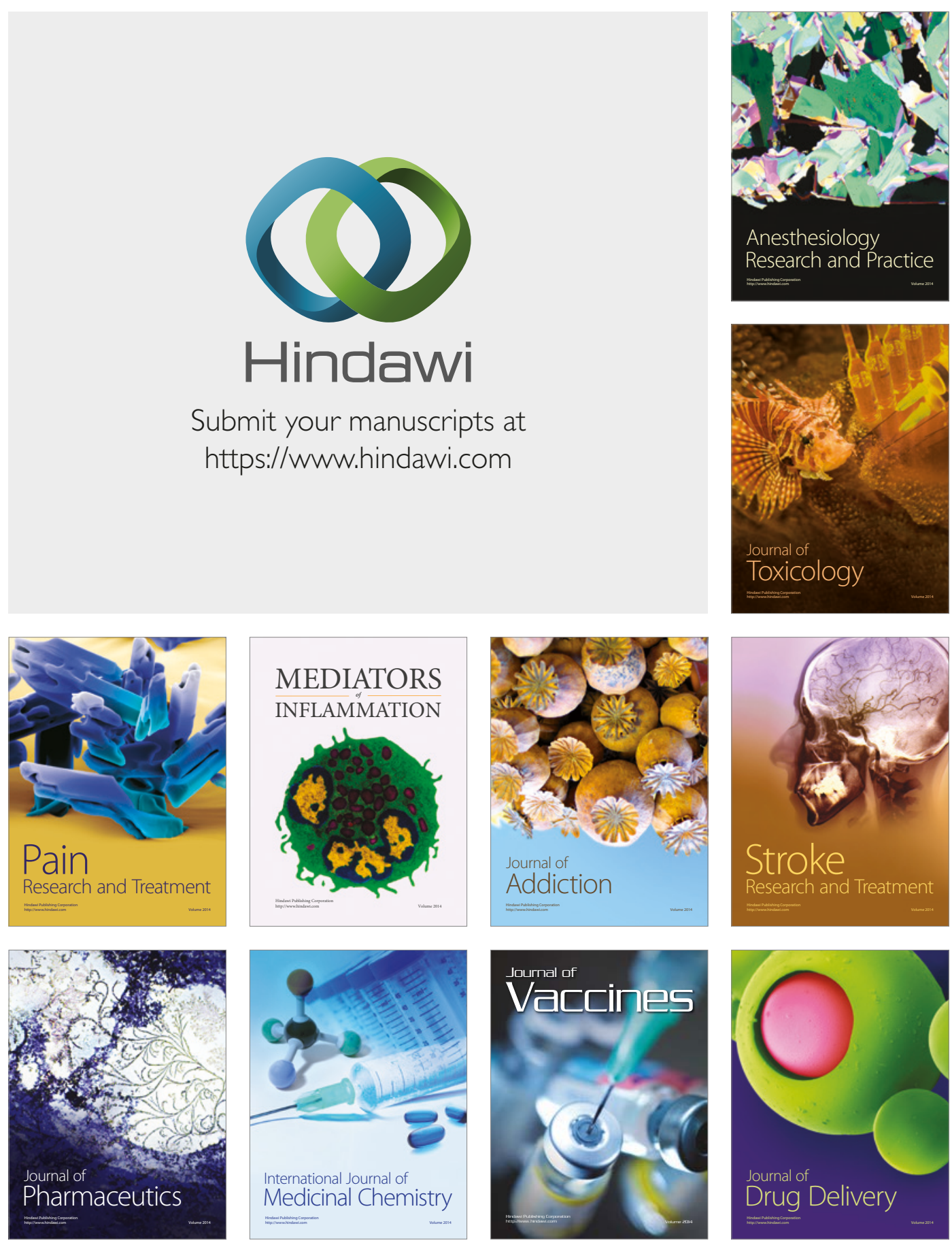